\title{
Team Membership Change and the Critical Role of Communication
}

\section{Ms. Amanda Deacon, University of Calgary}

Amanda is currently in her first year of her PhD in Industrial Organizational Psychology at the University of Calgary under the supervision of Dr. Tom O'Neill. Her area of focus is teams within organizational contexts and that results in a plethora of research conducted with engineering departments. Amandas lab uses these results to better prepare engineering students for teamwork within institutions of all kinds, educational and business.

\section{Dr. Tom O'Neill, University of Calgary}

O'Neill is a Professor of Industrial/Organizational Psychology and a leading expert in the areas of team dynamics, virtual teams, conflict management, personality, and assessment. He is director of the Individual and Team Performance Lab and the Virtual Team Performance, Innovation, and Collaboration Lab at the University of Calgary, which was built through a $\$ 500 \mathrm{~K}$ Canada Foundation for Innovation Infrastructure Grant. He also holds operating grants of over $\$ 300 \mathrm{~K}$ to conduct leading-edge research on virtual team effectiveness. Over the past 10 years, Tom has worked with organizations in numerous industries, including oil and gas, healthcare, technology, and venture capitals. He is currently engaged with the Schulich School of Engineering at the University of Calgary to train, develop, and cultivate soft-skill teamwork competencies in order to equip graduates with strong interpersonal and communication capabilities.

\section{Dr. Kartikeya Murari, University of Calgary}

Kartik is an Assistant Professor in the Department of Electrical and Computer Engineering at the University of Calgary. His research interests are in electrical and optical instrumentation and techniques for biomedical applications. He teaches undergraduate and graduate classes and is interested in ways to better prepare students for real-life learning and professional situations. 


\title{
Team Membership Change and the Critical Role of Communication
}

\begin{abstract}
In line with the engineering accreditation board's guidelines for program outcomes, this study narrows in on the ability of undergraduate engineers to function in foreign teams (although not multidisciplinary) and their ability to communicate effectively. The purpose of this research was to assess the effects of systematic membership change within teams and the role of communication on student's perceptions of learning.

In an attempt to mirror the reality of engineering work life, a systematic membership change was imposed on an electrical engineering class to situate students within a permanent team, while still engaging in the benefits and challenges of working and communicating with a new team. This emerged in the form of students working with a different team for one lab and attaining the experience of working with guest members in their permanent teams for four labs.
\end{abstract}

\section{Method}

The sample consisted of 174 second year engineering undergraduate students enrolled in the "Electronic Devices and Materials" course at the Schulich School of Engineering. Students were randomly assigned to a four-person team. The course contained five team labs and variables of interest were collected via online survey after each lab. The data was analyzed using multilevel growth modeling.

Results

Results found that communication was critical for individual's perceptions of learning. Individuals who reported high levels of communication reported significantly higher levels of perceptions of learning than those students who reported low levels of communication during the first lab. In addition, there was a significant difference in the trajectories of the students across time such that those who reported low levels of communication continued to decline in their selfreports of learning throughout the semester whereas those who reported high levels of communication remained high on perceptions of learning throughout the semester.

Furthermore, an important antecedent identified for an individuals likelihood to report high levels of communication within a team was the level of social identity that individual reported during the previous lab. High social identity was negatively related to following 
communication reports over time whereas low social identity was positively related to communication. These results will be discussed further in the paper.

\subsection{Introduction}

Much of the work done in organizations today is through the use of teams ${ }^{1}$. The use of teams in the engineering industry has become commonplace and with good reason. When used appropriately, successful teams can provide an advantage over individual efforts, whether that be in productivity, efficiency, or creativity ${ }^{2345}$. Today teams face new challenges. Team members interact with teams other than their own, leave temporarily, or are replaced by other organizational members and yet the core team must persist. Now more than ever, teams are being recognized as dynamic in nature, a far cry from the common assumption of static, with loose boundaries and fluid memberships ${ }^{6}$. It is not uncommon for engineers to face the challenge of working with constantly changing teams, and as such it is important to understand membership change, its overarching effects on outcomes, and how to survive it.

\section{Membership change}

Promotions, selection, layoffs, retirement, role transitions, and absenteeism are just a few reasons that members may be removed or added to a team ${ }^{7}$. More often than not multidisciplinary teams are formed and employees need to be accustomed to working with new team members who are brought on to a project. It is extremely important for teams to be able to react quickly and appropriately to changes in order to thrive ${ }^{8}$. While there are many types of membership change, in this study membership change pertains to one member of the "core" team temporarily leaving and being replaced with a temporary "guest" member from another team.

\section{Study contributions}

The purpose of this paper is to address the seemingly overlooked area of team research, and the challenges that can accompany working in a team when situated in an organization. This study simulated the common occurrence of membership change by employing a unique design to measure its accompanying effects on important student outcomes. Furthermore, the critical role that communication plays in the success of an individuals learning during membership change is highlighted, emphasizing the need to continue to develop this skill within students so that they may be better prepared to enter the workforce.

\section{Membership change and the effect on performance}

Current literature is mixed with respect to whether membership change is beneficial or harmful for teams. Studies report positive effects of membership change such as enhanced knowledge, skills, abilities, diversity, the ability to keep the group flexible and able to adapt in times of crises, integrating the team within the entire organization, and evidence of increased 
performance $^{791011}$. Disadvantages of membership change can be disruption to the team, it interrupts efficient group functioning in crises, and it strains members who have a hard time accepting and integrating new members ${ }^{37912}$. Membership change consistently has a positive effect on performance when teams adapt by focusing on information sharing within the team and utilize creativity that may be sparked by the addition of a new member. In essence, one of the strongest predictors of how well a team functions when dealing with new members can arguably be boiled down to the teams ability to communicate with all members of the team.

Communication is essential for teams to develop and update their knowledge structures when adaptation is required $^{13}$. The engineering accreditation board's guidelines for program outcomes has recognized the importance of communication in engineering graduates and has rightly highlighted it as an important student outcome and a program educational objective ${ }^{14}$. However, communication is not a simple construct and can be composed of many different facets. For the purpose of this study the construct "behavioural integration" was used as it identified three important components that were deemed measurable indicators of successful communication in a team.

\section{Behavioural integration}

Behavioral integration is defined as "the degree to which mutual and collective interaction exists within the group" $"$. Strong emphasis is to be put on "mutual and collective interaction'. As conceptualized by Hambrick (1994), behavioural integration is composed of three distinct features: information exchange, collaborative behavior, and joint decision-making. Field interviews confirmed that failure of behavioural integration can cause problems within teams such as poor coordination, failure to exchange important information, and trouble adapting to environmental shifts ${ }^{15}$.

The first dimension is information exchange, or commonly phrased as information sharing. Summers, Humphrey and Ferris (2012) found that information sharing between members ultimately led to stronger performance by minimizing the negative effects had on coordination during membership change. This information sharing can present itself in the quantity of ideas shared or the uniqueness of ideas shared, both of which aids teams ${ }^{16}$. Hambrick (1994) captures this in his dimension "information exchange" by stressing both quantity and quality of information exchange between members.

Following the exchange of information, Hambrick's (1994) second dimension focuses on collaborative behaviour to aid communication. When faced with a disruption in their normal processes due to membership change, adaptive teams must switch from implicit coordination, which relies on the anticipation of information given, to explicit coordination, which uses requests and communication to gather information ${ }^{17}$. Stein ${ }^{18}$ states that "communication with the self is insufficient", mandating the necessity of communicating ideas to individuals other than 
oneself if the primary intent is to share and gain understanding from others. This leads into the final dimension, joint decision-making.

By making decisions as a team, every idea can be debated thoroughly so as to confirm all members understood and have assessed the merit of each idea. This increases the chance that the team will choose the best option together versus an adequate option individually. Members must successfully integrate into the team these unique and relevant ideas to increase task performance $^{16}$. All three steps of behavioural integration are challenged when new members are introduced into the team and yet it is only through communication that teams may thrive at each area and as a whole.

I define core members as those who are part of the team currently, have been part of the team in the past and believe they will be part of the team in the near future. Core members are those who can leave the team to work with another group and yet are still acutely aware which team they share membership with. In contrast, I define guest members as those who are working with a team but are aware that it is temporary. They do not identify with this team, they have no past with this team, and they know they will not have continued membership with this team.

Teams are not isolated in time; they bring together individuals with different pasts, create history themselves, and behave in accordance with where members think their future lies ${ }^{7}$. A teams' past can affect their present culture and how members behave. It is with this in mind that that the level of social identity the individual perceived there to be with their team was considered as a predictor of the effectiveness of behavioural integration.

\section{Social identity}

Ashforth and Mael $^{19}$ recognize social identity to be a perception of an individual's oneness with a group, which can differ in levels of salience, and ultimately guides member's actions as they struggle to have them be congruent with their identity in order to reinforce their identity. It can have a very powerful effect on affect and behaviour ${ }^{20}$.

One of the most fascinating effects that occur from social identity is the natural categorization of in-groups and out-groups. In-groups and out-groups are a normal occurrence of boundaries that teams make when forming a social identity ${ }^{7}$. When member similarity is high versus low, there is more information sharing that occurs within a team ${ }^{16}$. Guest members to the group are viewed as less similar to the rest of the core team and this affects the receptivity they receive when inputting ideas from the core members ${ }^{12} 21$. This level of ostracism to nonprototypical members, or guest members, can severely inhibit future contributions by decreasing member's sense of belongingness and motivation ${ }^{22}$. If no superordinate identity can be found between guest members and core members then evidence shows core members are unlikely to accept the guest members contributions ${ }^{23}$ thus limiting successful behavioural integration. 
Hypothesis 1: Over time, a strong social identity will have a negative effect on individual's perceptions of behavioural integration.

Perceptions of learning

Perceptions of learning was chosen to assess if behavioural integration was meaningful within teams that experience membership change. This outcome was chosen as it maps onto Wageman, Hackman, and Lehman's 2005 one dimension of team effectiveness, "the team experience contributes to the learning and well being of the team members" ${ }^{24}$.

When there is a division between members within a team, in this case between core members and guest members, members are more likely to communicate and share with the group they identify with ${ }^{25}$. Unfortunately, in order for individuals to be able to learn, there must be sharing and collaboration between all members, core members and guest members. By segregating information and communication, member's psychological safety is reduced and so is subsequent perceptions of learning ${ }^{25}$. By sharing information and communicating, members may find an increase in their intrinsic motivation, believe themselves to be more capable, and find the work interesting, all of which has been positively related to perceptions of learning ${ }^{26}$. Information exchange, collaborating and joint decision-making between members is hypothesized to increase the chance that members will learn.

Hypothesis 2: There will be a positive relationship between individual behavioural integration and individual perceptions of learning.

Figure 1. Overview of Hypotheses

Time $1 * *$

$\underline{\text { Team State }}$
Time 2

Behavioural Integration

H1
H2
Time 2

Outcome

Social Identity $\longrightarrow$ Individual $\mathrm{BI}^{*} \longrightarrow$ Perceptions of Learning

*BI = Behavioral integration. Individual behavioural integration is composed of three dimensions including information exchange, collaborative behavior, and joint decision-making.

**Time 1 and Time 2 are given as examples. Time points in the study range from Time 0 to Time 4 , with 5 time points in total.

\subsection{Method}

Participants

Participants were 174 second year engineering undergraduate students enrolled in the "Electronic Devices and Materials" course at the Schulich School of Engineering during the 
2015 Winter Semester. Participation was voluntary and participants were compensated with a $\$ 5$ coffee card and .5\% grade per survey. Participants were randomly configured into 44 four-person teams.

\section{Procedure}

There were five labs in total and data was collected after each one. During the first lab, students were given an overview of the study, provided with some basic team building so that they may become accustomed to their groups, and completed an introductory lab materials project. They were subsequently informed about the online survey process and completed their first survey that evening. The students received .5\% towards their course grade for completing each survey. The following four labs each consisted of one assignment that was completed as a team with labs being worth a cumulative $10 \%$ of the student's final grade. Upon completion of the lab assignment, teams had the opportunity to complete the online survey containing the desired scales of measurement. Each lab successively after the first lab (hereby labeled as lab 0), included a membership change for each team. The membership change was composed of one member from each core team visiting a new team for the entirety of the lab. Each core team received one guest member from a separate team for the entirety of the lab to replace their missing core member. All participants were given a performance grade based off of the team that they were in for that specific lab, regardless of whether it was their core team or not. Upon completion of the lab, each member returned to his or her core team.

Over the course of the semester, each member of a team had one opportunity to be a guest in another team for the sum of one lab. For each lab, following lab 0 , each core team had one guest member who was working with them for the sum of one lab. No individual was a visiting member on more than one occasion. No team had more than one guest member at any given lab, as can be viewed in Figure 2.

Figure 2. Representation of Membership Change within Teams

$\begin{array}{lllllll}\text { T0* } & \text { ABCD } & 1234 & \$ \% \& ! & \text { WXYZ } & 6789 & \text { nopq } \\ \text { T1 } & \text { ABCq } & 123 \mathrm{D} & \$ \% \& 4 & \text { WXY! } & 678 Z & \text { nop9 } \\ \text { T2 } & \text { AB8D } & 12 \mathrm{p} 4 & \$ \% C ! & \text { WX3Z } & 67 \& 9 & \text { noYq } \\ \text { T3 } & \text { AXCD } & 1734 & \$ o \& ! & \text { WBYZ } & 6289 & \text { n\%pq } \\ \text { T4 } & \text { \$BCD } & \text { W234 } & 6 \% \& ! & \text { nXYZ } & \text { A789 } & 1 \text { opq }\end{array}$

* Time 0 represents member's original teams. Each team at any given time point after Time 0 was composed of three original or "core" members and one guest member. No team had more than one guest member from the same team throughout the duration of the course. The only 
individuals a member had contact with on more than one occasion were those individuals who were apart of that member's core team.

\section{Materials}

All scales were framed in order to have members reflect on the most recent project they completed with that specific team, whether it be the members home team or a guest team.

Behavioral integration. Behavioural integration was composed of three scales to assess three sections as defined by Hambrick (1994): collaborative behaviour, information exchange, and joint-decision making. Combining the three scales and using the mean resulted in obtained behavioural integration scores for an individual. All items were measured using a five-point Likert scale where 1= "strongly disagree" and 5= "strongly agree". While researchers have previously created items, new items were created for each dimension to fit this specific context. The questions can be found in Table 1. Reliabilities for the scale can be found in appendix A.

Table 1. Behavioural Integration Items

1. I felt like all members helped each other out when needed

2. I felt like I could openly discuss other members ideas with the team

3. I felt like all members of the team encouraged me to participate

4. I felt like when I shared an idea other members seriously considered it

5. I feel like I was able to share my ideas, even when they were different from the rest of the team

6. I felt like the other members freely shared their ideas with me

7. I felt like my ideas were incorporated, in some way or another, into the final product

8. I felt like an active member in the final decision process

9. We made the final decision/product as a group

Social identity. Social identity was assessed using a three dimension, twelve-item scale adapted from Stoner, Perrewé and Hofacker ${ }^{27}$. All items were measured using a five-point Likert scale where 1= "strongly disagree" and 5= "strongly agree". Sample items included, "I am a member of this team", and "I perceive myself to be similar to other members of this team".

Perceptions of learning. Perceptions of learning was assessed using a seven-item scale adapted from Pintrich and De Groot ${ }^{26}$ which included such items as, "It was important for me to learn what was being taught in the most recent project". Participants were asked to rate items on a seven-point scale where 1= "strongly disagree" and 7= "strongly agree".

\section{Analytic approach}

Hierarchical linear modeling was used to assess the longitudinal multilevel data. In order to assess behavioral integration, Time was considered a level 1 variable with all individual state 
variables considered level 2. In other words, the level 2 gammas tested whether each (preceding) score of social identity, as a time-varying predictor, predicted the intercept and slope of (subsequent) behavioural integration over time. To assess the outcome, Time was Level 1 and behavioural integration was Level 2. In other words, the level 2 gammas tested whether behavioural integration, as a time-varying predictor measured at the same time point as the time varying criterion, predicted the intercept (mean) and slope of the criterion over time.

\subsection{Results}

\section{Preliminary analyses}

Prior to the data being analyzed, cleaning was conducted on the data set, as suggested by Tabachnick and Fidell ${ }^{28}$. At time of completion, a total of 679 observations remained across all time points out of the original 775 observations. Individual-level correlations were run contrasting each time point variable as to not violate the assumption of independence (appendix A), and accompanying them are the corresponding means and standard deviations for each variable.

As the scale for behavioural integration was created for the purpose of this study, a confirmatory factor analysis was conducted on the 9 behavioral integration items. This was done for each time point. The statistical software $r$ and the program Lavaan were used to run the analyses. Upon testing a one, two and three factor model, the three factor model that allowed for correlation between dimensions was deemed to fit the data best. Across the five time periods there were between 139-145 cases. With 24 degrees of freedom, the p-value ranged between $<.001-.003$. The $-2 \log$ likelihood ranged between 1011.78-1315.94. RMSEA failed to achieve a value below the recommended .08 on four of the occasions (.08-.16) and the chi-square was significant for every lab (47.64-110.40). However, fit indexes improved at each lab and the CFI and SRMR show moderate to good fit indexes across labs (.88-.97 and .04-.08, respectively). Taken as a whole, the results show moderate support for a three-factor model at this time.

\section{Analyses}

Social identity, psychological safety and behavioral integration. Following the suggested guidelines of Bliese and Ployhart ${ }^{29}$ and Ployhart, Holtz and Bliese ${ }^{30}$, there are five stages to multilevel growth modeling. These stages are, (1) examining the properties of the dependent variable, (2) modeling in time, (3) modeling in slope variability, (4) modeling error structures, (5) and predicting intercept variation as well as slope variation with level two predictors.

Hypothesis 1 stated that over time, a strong social identity will have a negative effect on individuals' perceptions of behavioural integration. To begin testing this, a null model was estimated. The mean intercept at time zero for behavioural integration (BI) was 3.93 on a scale of $1-5$ and $33 \%$ of the variance found in individual's score of behavioural integration could be attributed to the individuals themselves. Progressing through the following stages as described 
previously, analysis reveled that there was no effect of time on individuals behavioural integration, with an average intercept value of 3.95 and a .05 increase at each consecutive time point, with $t(94)=.67, S E=.02, p=.50$. Furthermore, in comparison to the previous model ($2 L L=-405.7)$, allowing the slope to vary across individuals did not significantly improve the model $(-2 L L=-405.7, p=.54)$, however allowing for autocorrelation in the data did $(-2 L L=-$ 402.75, $p=.008)$.

Further analyses confirmed that social identity was not related to initial levels of behavioural integration (Table 2). However, it was revealed that there was a significant effect of social identity on the slope of individual's behavioural integration (Table 3). This can be viewed in Figure 3. In summary, social identity accounted for significant slope variation in behavioural integration and therefore, $\mathrm{H} 1$ at the individual level was partially supported.

Table 2. Relationship between individuals' social identity and BI intercept

\begin{tabular}{llllll}
\hline Variable & Estimate & SE & d.f & t-value & P-value \\
\hline Intercept & 4.19 & 0.20 & 313 & 20.78 & $p<.001$ \\
Time & -.01 & 0.01 & 313 & 0.79 & 0.43 \\
Social Identity & 0.38 & 0.03 & 313 & -1.28 & 0.20 \\
\hline
\end{tabular}

Table 3. Relationship between individuals' social identity and BI intercept and slope

\begin{tabular}{llllll}
\hline Variable & Estimate & SE & d.f & t-value & P-value \\
\hline Intercept & 3.50 & 0.33 & 312 & 10.74 & $p<.001$ \\
Time & 0.45 & 0.14 & 312 & 3.13 & $p<.001$ \\
Social Identity & 0.12 & 0.09 & 312 & 1.39 & 0.16 \\
Time: Social & -0.12 & 0.04 & 312 & -3.03 & $p<.001$ \\
Identity & & & & & \\
\hline
\end{tabular}


Figure 3. Social Identity And Time Interaction On Behavioral Integration Ratings.

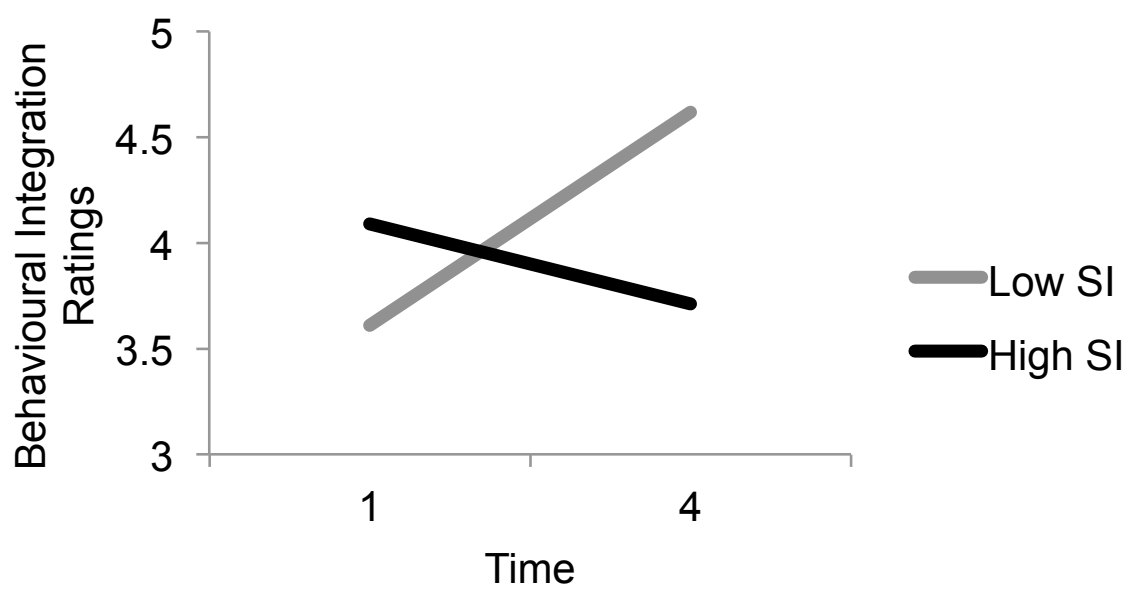

Figure 3. Social identity and time interaction on behavioral integration ratings. Time begins at 1 on a possible scale of 0-4 as previous scores of social identity were used as predictors for BI and as such only BI from time 1-4 were observed. The BI scale ranges from 1-5.

Behavioral integration and perceptions of learning. Hypothesis 2 specified that there would be a positive relationship between individual behavioural integration and individual perceptions of learning. To begin, a null model was estimated. The average intercept at time zero for perceptions of learning was 3.88 on a scale of $1-5$ and $46 \%$ of the variance found in an individual's score of perceptions of learning could be attributed to the individuals themselves. Continued analysis revealed (a) there is a significant quadratic trend between time and perceptions of learning, with an average intercept value of 3.97 and a .05 increase at each consecutive time point, with $t(521)=4.88, S E=.01, p<.001$. Furthermore, in comparison to the previous model $(-2 L L=--559.46)$, allowing the slope to vary across individuals did significantly improve the model $(-2 L L=-553.46, p=.002)$, however allowing for autocorrelation in the data $\operatorname{did} \operatorname{not}(-2 L L=-553.42, p=.77)$.

In the fifth stage, analysis revealed that BI was positively related to initial levels of perceptions of learning (Table 4). Finally, BI was inserted into the model in an attempt to explain a unique amount of variance in the time-perceptions of learning slope (Table 5). This too revealed that there was a significant effect of BI on the slope of individual's perceptions of learning (Figure 4). In summary, BI accounted for significant slope variation in perceptions of learning over time as well as for intercept variation and therefore, H2 was supported. 
Table 4. Relationship between individuals' BI and perceptions of learning intercept

\begin{tabular}{llllll}
\hline Variable & Estimate & SE & d.f & t-value & P-value \\
\hline Intercept & 2.38 & 0.14 & 521 & 17.00 & $p<.001$ \\
Time & -.01 & 0.01 & 521 & -0.54 & 0.59 \\
BI & 0.38 & 0.03 & 521 & 11.26 & $p<.001$ \\
\hline
\end{tabular}

Table 5. Relationship between individuals' BI and perceptions of learning intercept and slope

\begin{tabular}{llllll}
\hline Variable & Estimate & SE & d.f & t-value & P-value \\
\hline Intercept & 2.96 & 0.22 & 520 & 13.36 & $p<.001$ \\
Time & -0.29 & 0.09 & 520 & -3.39 & $p<.001$ \\
BI & 0.24 & 0.06 & 520 & 4.28 & $p<.001$ \\
Time: BI & 0.07 & 0.02 & 520 & 3.35 & $p<.001$ \\
\hline
\end{tabular}

Figure 4. Behavioural Integration and Time Interaction on Perceptions of Learning Ratings

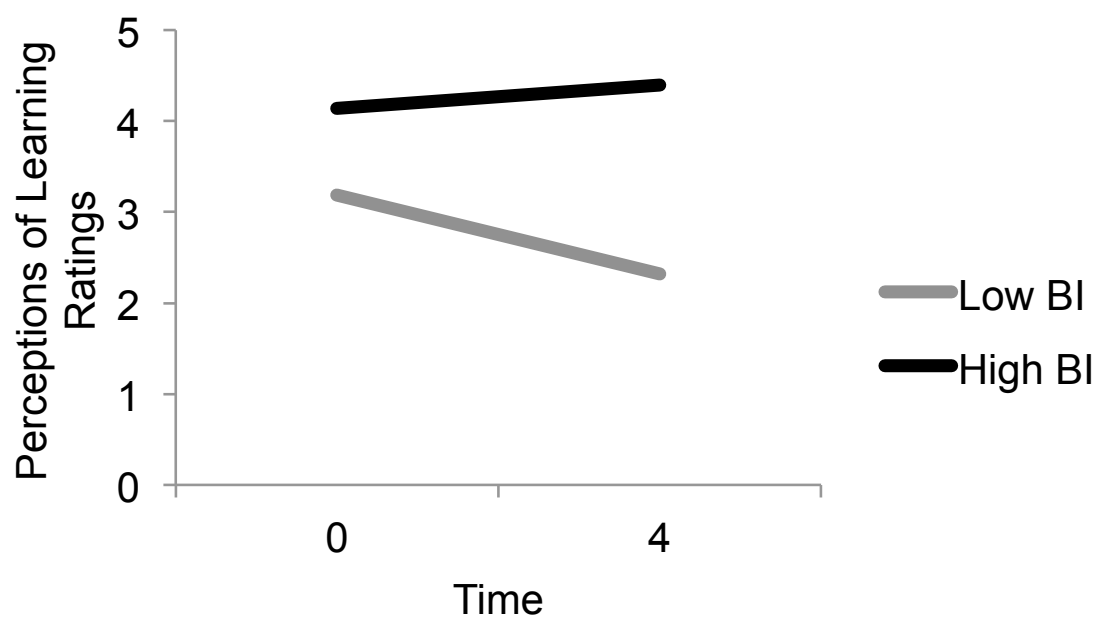

Figure 4. Behavioural integration and time interaction on perception of learning ratings. Time spans from $0-4$ as BI and perceptions of learning were assessed simultaneously providing a total of 5 time points. The BI scale ranges from 1-5.

\subsection{Discussion}

The primary purpose of this research paper was to examine the role of communication, observed as behavioral integration, as an important component of how individuals managed membership change and the challenge of working in foreign teams. The present study identified behavioural integration as an important and unique predictor of students perceptions of learning, as well as identifying social identity to be an indicator of behavioural integration. 
The contributions of this study are twofold: it highlights the importance of communication in situations when individuals are working with new teams or new members and its subsequent effects of individuals perceptions of learning. In addition, this study provides a novel method that may be employed in labs to better prepare students for working in organizational teams through the enhancement of their communication skills in accordance with $\mathrm{ABET}^{14}$.

\section{Social identity on behavioural integration}

Social identity was shown to effect perceived levels of behavioural integration. Analyses revealed significantly different trajectories in perceptions of behavioral integration for individuals high on social identity versus those low on social identity. Individuals who reported high levels of social identity followed a negative trajectory across time, with their BI scores continuously decreasing at each time point. In contrast, those individuals that reported low social identity experienced a positive trajectory over time with their reports of BI increasing as time progressed. Those with a high social identity may have found the continuing shift in members, including themselves at one time point to another team, to be stressful as they could not relate to "outside" team members, and subsequently found their perceptions of BI decreasing with every lab. Those with low social identity did not identify with their team to the same extent and were more likely able to adapt to the change in members with increased efficiency and, as they became accustomed to the change, showed an increase in their communication with the team. Furthermore, their time being a visiting guest member at another team was more likely to be successful in terms of BI because of their lack of inhibition with communicating to "outside" members.

Practically speaking, this finding highlights what is commonly voiced in student teams, which is that students do prefer to stay in a consistent team throughout their semesters. However this research finds that these individuals are also the ones who struggle the most with communicating to new members and teams. Given the implausibility of a student working in a stable team throughout their careers, and the potential added strain of working in a multidisciplinary team, students may benefit from being exposed to this type of design in the classroom.

\section{Behavioural Integration on perceptions of learning}

Individual behavioural integration had a significant effect on an individual's perception of learning. More specifically, it had a significant effect on the starting point and the trajectory. Individuals who reported high initial levels of behavioural integration, in contrast to those who reported low, stated significantly higher perceptions of learning. Furthermore, those who reported high levels of behavioural integration continued on a positive trajectory whereas those who reported low levels of behavioural integration embarked on a negative trajectory. This would imply that individuals who did not perceive themselves to be effectively communicating and integrated into teams had an increasingly difficult time perceiving learning to be occurring as 
time progressed. Research has shown that sharing information and engaging in high levels of communication results in individuals increased interest in work, and subsequently, higher perceptions of learning ${ }^{26}$. It is possible that upon initial levels of low behavioural integration within teams, individuals became more disengaged and demotivated as time continued. This then led to continuously lower levels of perceptions of learning. In contrast, individuals who started out high on behavioural integration may have retained/increased their level of engagement, maintaining their high levels of learning.

A second potential explanation for the interaction effect for $\mathrm{BI}$ on perceptions of learning would be that individuals who felt integrated were able to better handle the constant flux in membership change and continue to learn despite the disruption, whereas those low on behavioural integration were more affected by the constant change. In this instance, behavioural integration would act as a buffering effect of the change on individual's ability to learn, once again emphasizing communication's importance within teams in times of stress.

\section{Strengths and limitations}

The greatest strength of this study lies in the design. To the researcher's knowledge, a study that embodies a design such as the one used in this experiment has not been conducted. The designed dictated that no two people from the same core team ever visited the same guest team, even at different time periods. This minimized the cultural contamination between teams. Secondly, the use of a previous predictive variable on subsequent behavioural integration scores increased reliability in claiming casual relationships between constructs. Similarly, the overall use of five time points is rare within a team study and this provided confidence in the robustness of the results as they were proven to be sustained across a longer time period.

One of the limitations of this study is its generalizability to all types of membership change. This study observed a specific form but future research would do well to identify if the findings hold true if the frequency of membership changes, when it occurs during the project is different, whether it is anticipated or a surprise, and if the members change temporarily or permanently ${ }^{70}$ ${ }^{12}$. Additionally, research should examine open-ended tasks that require increased levels of team deliberation, as these were closed, and employ a full multilevel mediation technique.

\subsection{Conclusion}

These findings highlight the importance of communication in student's ability to work in fluid teams effectively and whether they perceive themselves to gain new knowledge upon completion of the project. $\mathrm{ABET}^{14}$ has highlighted the importance of communication installed in students during their tenure with the program and yet this research has shown that many students still struggle with this when faced with stressors, ironically a time that has proven to be even more critical for communication to be present in order for individuals to succeed. 


\section{Bibliography}

1. Marks, M. A., Mathieu, J. E., \& Zaccaro, S. J. (2001). A temporally based framework and taxonomy of team processes. Academy of Management Review, 26(3), 356-376.

2. Choi, H., \& Thompson, L. (2005). Old wine in a new bottle: Impact of membership change on group creativity. Organizational Behavior and Human Decision Processes, 98(2), 121-132. doi:http://dx.doi.org/10.1016/j.obhdp.2005.06.003

3. Hirst, G. (2009). Effects of membership change on open discussion and team performance: The moderating role of team tenure. European Journal of Work and Organizational Psychology, 18(2), 231-249. doi:http://dx.doi.org/10.1080/13594320802394202

4. McGrath, J. E., Arrow, H., \& Berdahl, J. L. (2000). The study of groups: past, present, and future. Personality and Social Psychology Review, 4(1), 95-105.

5. Summers, J. K., Humphrey, S. E., \& Ferris, G. R. (2012). Team member change, flux in coordination, and performance: Effects of strategic core roles, information transfer, and cognitive ability. Academy of Management Journal, 55(2), 314-338.

6. Tannenbaum, S. I., Mathieu, J. E., Salas, E., \& Cohen, D. (Mar 2012). Teams are changing: Are research and practice evolving fast enough? Industrial and Organizational Psychology: Perspectives on Science and Practice, 5(1), 2-24. doi:http://dx.doi.org/10.1111/j.1754-9434.2011.01396.x

7. Arrow, H., \& McGrath, J. E. (1995). Membership dynamics in groups at work: A theoretical framework. Research in organizational behavior, 17, 373-373.

8. Rosen, M. A., Bedwell, W. L., Wildman, J. L., Fritzsche, B. A., Salas, E., \& Burke, C. S. (2011). Managing adaptive performance in teams: Guiding principles and behavioral markers for measurement. Human resource management review, 21(2), 107-122.

9. Arrow, H., \& McGrath, J. E. (1993). Membership matters how member change and continuity affect small group structure, process, and performance. Small group research, 24(3), 334-361.

10. Mathieu, J.E., Tannenbaum, S.I., Donsbach, J.S., Alliger, G.M. (2014). A Review and Integration of Team Composition Models: Moving Toward a Dynamic and Temporal Framework. Journal of Management Vol. 40 No. 1, 130-160 DOI: 10.1177/0149206313503014

11. Sundstrom, E., De Meuse, K. P., \& Futrell, D. (1990). Work teams: Applications and effectiveness. American psychologist, 45(2), 120.

12. Rink, F. A., \& Ellemers, N. (Jun 2009). Temporary versus permanent group membership: How the future prospects of newcomers affect newcomer acceptance and newcomer influence. Personality and Social Psychology Bulletin, 35(6), 764-775. doi:http://dx.doi.org/10.1177/0146167209333177

13. Burke, C. S., Stagl, K. C., Salas, E., Pierce, L., \& Kendall, D. (2006). Understanding team adaptation: A conceptual analysis and model. Journal of Applied Psychology, 91(6), 1189.

14. Criteria for accrediting engineering programs, 2015-2016. (n.d.) In Accreditation Board for Engineering and Technology. Retrieved from http://www.abet.org/accreditation/accreditation-criteria/criteria-for-accreditingengineering-programs-2015-2016/

15. Hambrick, D. C. (1994). Top management groups: A conceptual integration and reconsideration of the" team" label. Research in organizational behavior, 16, 171-171.

16. Mesmer-Magnus, J. R., \& DeChurch, L. A. (2009). Information sharing and team performance: a metaanalysis. Journal of Applied Psychology, 94(2), 535.

17. Serfaty, D., Entin, E. E., \& Volpe, C. (1993). Adaptation to stress in team decision-making and coordination. In Proceedings of the Human Factors and Ergonomics Society Annual Meeting (Vol. 37, No. 18, pp. 12281232). SAGE Publications.

18. Stein, M. I. (1953). Creativity and culture. The journal of psychology, 36(2), 311-322.

19. Ashforth, B. E., \& Mael, F. (1989). Social identity theory and the organization. Academy of management review, 14(1), 20-39. 
20. Turner, J. C. (1985). Social categorization and the self-concept: A social cognitive theory of group behavior. Advances in group processes, 2, 77-122.

21. Van Knippenberg, D. (2000). Work motivation and performance: A social identity perspective. Applied psychology, 49(3), 357-371.

22. O'Reilly, J., \& Robinson, S. L. (2009). The Negative Impact Of Ostracism On Thwarted Belongingness And Workplace Contributions. In Academy of Management Proceedings (Vol. 2009, No. 1, pp. 1-7). Academy of Management.

23. Kane, A. A., Argote, L., \& Levine, J. M. (2005). Knowledge transfer between groups via personnel rotation: Effects of social identity and knowledge quality. Organizational Behavior and Human Decision Processes, 96(1), 56-71.

24. Wageman, R., Hackman, J. R., \& Lehman, E. (2005). Team Diagnostic Survey Development of an Instrument. The Journal of Applied Behavioral Science, 41(4), 373-398.

25. Lau, D. C., \& Murnighan, J. K. (2005). Interactions within groups and subgroups: The effects of demographic faultlines. Academy of Management Journal, 48(4), 645-659.

26. Pintrich, P. R., \& De Groot, E. V. (1990). Motivational and self-regulated learning components of classroom academic performance. Journal of educational psychology, 82(1), 33.

27. Stoner, J., Perrewé, P. L., \& Hofacker, C. (2011). The Development and Validation of the Multi-Dimensional Identification Scale (MDIS). Journal of Applied Social Psychology, 41(7), 1632-1658.

28. Tabachnick, B. G., \& Fidell, L. S. (2001). Cleaning up your act: screening data prior to analysis. Using multivariate statistics, 5, 61-116.

29. Bliese, P. D., \& Ployhart, R. E. (2002). Growth modeling using random coefficient models: Model building, testing, and illustrations. Organizational Research Methods, 5(4), 362-387.

30. Ployhart, R. E., Holtz, B. C., \& Bliese, P. D. (2002). Longitudinal data analysis: Applications of random coefficient modeling to leadership research. The leadership quarterly, 13(4), 455-486.

\section{APPENDIX A}

\section{Individual Level Correlations}

Table 6. Descriptive statistics and correlations at Time 1

\begin{tabular}{llllllllll}
\hline & Variable & $\underline{M}$ & $\underline{S D}$ & $\underline{1}$ & $\underline{2}$ & $\underline{3}$ & $\underline{4}$ & $\underline{5}$ & $\underline{6}$ \\
\hline 1 & $\begin{array}{l}\text { Social } \\
\text { Identity }\end{array}$ & 3.73 & 0.54 & $(.87)$ & & & & & \\
2 & $\begin{array}{l}\text { Perceptions } \\
\text { of Learning }\end{array}$ & 3.99 & 0.53 & $.24^{*}$ & $(.80)$ & & & & \\
& $\begin{array}{l}\text { BI - } \\
\text { Collaborative }\end{array}$ & & & & & & & & \\
& $\begin{array}{l}\text { Behaviour } \\
\text { BI - }\end{array}$ & 4.00 & 0.71 & $.51^{* *}$ & 0.17 & $(.75)$ & & & \\
4 & $\begin{array}{l}\text { Information } \\
\text { Exchange } \\
\text { BI - Joint }\end{array}$ & 4.00 & 0.59 & $.49^{* *}$ & $.28^{* *}$ & $.61^{* *}$ & $(.73)$ & & \\
5 & $\begin{array}{l}\text { Decision } \\
\text { Making }\end{array}$ & 3.81 & 0.73 & $.49^{* *}$ & $.20^{*}$ & $.62^{* *}$ & $.61^{* *}$ & $(.78)$ & \\
6 & $\begin{array}{l}\text { Behavioural } \\
\text { Integration }\end{array}$ & 3.93 & 0.59 & $.58^{* *}$ & $.25^{* *}$ & $.87^{* *}$ & $.83^{* *}$ & $.87^{* *}$ & $(.88)$ \\
\hline Note. ${ }^{*} p<.05, * * p<.01 . N=105$. & & & & &
\end{tabular}


Table 7. Descriptive statistics and correlations at Time 2

\begin{tabular}{|c|c|c|c|c|c|c|c|c|c|}
\hline & Variable & $\underline{M}$ & $\underline{S D}$ & $\underline{1}$ & $\underline{2}$ & $\underline{3}$ & $\underline{4}$ & $\underline{5}$ & $\underline{6}$ \\
\hline 1 & $\begin{array}{l}\text { Social } \\
\text { Identity }\end{array}$ & 3.7 & 0.60 & $(.88)$ & & & & & \\
\hline 2 & $\begin{array}{l}\text { Perceptions } \\
\text { of Learning } \\
\text { BI - }\end{array}$ & 3.82 & 0.64 & $.28 * *$ & $(.83)$ & & & & \\
\hline 3 & $\begin{array}{l}\text { Collaborative } \\
\text { Behaviour } \\
\mathrm{BI}-\end{array}$ & 3.98 & 0.79 & $.71 * *$ & $.23^{*}$ & $(.86)$ & & & \\
\hline 4 & $\begin{array}{l}\text { Information } \\
\text { Exchange } \\
\text { BI - Joint }\end{array}$ & 3.93 & 0.65 & $.49 * *$ & $.26 * *$ & $.62 * *$ & $(.83)$ & & \\
\hline 5 & $\begin{array}{l}\text { Decision } \\
\text { Making }\end{array}$ & 3.81 & 0.67 & $.57 * *$ & 0.18 & $.74 * *$ & $.70 * *$ & $(.77)$ & \\
\hline 6 & $\begin{array}{l}\text { Behavioural } \\
\text { Integration }\end{array}$ & 3.91 & 0.62 & $.67 * *$ & $.25 * *$ & $.89 * *$ & $.85 * *$ & $.91 * *$ & $(.91)$ \\
\hline
\end{tabular}

Note. ${ }^{*} p<.05, * * p<.01 . N=105$. Guest competency $n=64$

Table 8. Descriptive statistics and correlations at Time 3

\begin{tabular}{|c|c|c|c|c|c|c|c|c|c|}
\hline & Variable & $M$ & $\underline{S D}$ & $\underline{1}$ & $\underline{2}$ & $\underline{3}$ & $\underline{4}$ & 5 & 6 \\
\hline 1 & $\begin{array}{l}\text { Social } \\
\text { Identity }\end{array}$ & 3.85 & 0.65 & $(.92)$ & & & & & \\
\hline 2 & $\begin{array}{l}\text { Perceptions } \\
\text { of Learning } \\
\text { BI - }\end{array}$ & 3.75 & 0.59 & $.53 * *$ & $(.82)$ & & & & \\
\hline 3 & $\begin{array}{l}\text { Collaborative } \\
\text { Behaviour } \\
\mathrm{BI}-\end{array}$ & 4.18 & 0.67 & $.76^{* *}$ & $.51 * *$ & $(.84)$ & & & \\
\hline 4 & $\begin{array}{l}\text { Information } \\
\text { Exchange } \\
\text { BI - Joint }\end{array}$ & 4.05 & 0.64 & $.65 * *$ & $.45 * *$ & $.72 * *$ & $(.87)$ & & \\
\hline 5 & $\begin{array}{l}\text { Decision } \\
\text { Making } \\
\text { Behavioural } \\
\text { Integration }\end{array}$ & 3.93 & $\begin{array}{l}0.67 \\
0.57 \\
\end{array}$ & $\begin{array}{l}.63 * * \\
.77 * *\end{array}$ & $\begin{array}{l}.51 * * \\
.55 * *\end{array}$ & $\begin{array}{l}.69 * * \\
.91 * *\end{array}$ & $\begin{array}{l}.62 * * \\
.87 * *\end{array}$ & $\begin{array}{l}(.79) \\
.87 * *\end{array}$ & $(.90)$ \\
\hline
\end{tabular}

Note. ${ }^{*} p<.05, * * p<.01 . N=105$. Guest competency $n=82$

Table 9. Descriptive statistics and correlations at Time 4

\begin{tabular}{|c|c|c|c|c|c|c|c|c|c|}
\hline & Variable & $\underline{M}$ & $\underline{S D}$ & $\underline{1}$ & $\underline{2}$ & $\underline{3}$ & $\underline{4}$ & $\underline{5}$ & $\underline{6}$ \\
\hline 1 & $\begin{array}{l}\text { Social } \\
\text { Identity }\end{array}$ & 3.77 & 0.66 & $(.92)$ & & & & & \\
\hline 2 & $\begin{array}{l}\text { Perceptions } \\
\text { of Learning } \\
\text { BI - }\end{array}$ & 3.9 & 0.66 & $.44 * *$ & $(.85)$ & & & & \\
\hline 3 & $\begin{array}{l}\text { Collaborative } \\
\text { Behaviour } \\
\mathrm{BI}-\end{array}$ & 4.08 & 0.71 & $.82 * *$ & $.44^{* *}$ & $(.88)$ & & & \\
\hline 4 & $\begin{array}{l}\text { Information } \\
\text { Exchange } \\
\text { BI - Joint }\end{array}$ & 3.99 & 0.73 & $.66^{* *}$ & $.46^{* *}$ & $.75^{* *}$ & (.89) & & \\
\hline 5 & $\begin{array}{l}\text { Decision } \\
\text { Making }\end{array}$ & 3.87 & 0.8 & $.63^{* *}$ & $.53 * *$ & $.69 * *$ & $.83 * *$ & $(.90)$ & \\
\hline 6 & $\begin{array}{l}\text { Behavioural } \\
\text { Integration }\end{array}$ & 3.98 & 0.68 & $.76^{* *}$ & $.52 * *$ & $.88 * *$ & $.94 * *$ & $.92 * *$ & $(.94)$ \\
\hline
\end{tabular}

Note. ${ }^{*} p<.05, * * p<.01 . N=105$. Guest competency $n=75$ 
Table 10. Descriptive statistics and correlations at Time 5

\begin{tabular}{|c|c|c|c|c|c|c|c|c|c|}
\hline & Variable & $\underline{M}$ & $\underline{S D}$ & $\underline{1}$ & 2 & $\underline{3}$ & $\underline{4}$ & $\underline{5}$ & $\underline{6}$ \\
\hline 1 & $\begin{array}{l}\text { Social } \\
\text { Identity }\end{array}$ & 3.77 & 0.65 & $(.92)$ & & & & & \\
\hline 2 & $\begin{array}{l}\text { Perceptions } \\
\text { of Learning } \\
\mathrm{BI}-\end{array}$ & 3.97 & 0.63 & $.40 * *$ & $(.87)$ & & & & \\
\hline 3 & $\begin{array}{l}\text { Collaborative } \\
\text { Behaviour } \\
\mathrm{BI}-\end{array}$ & 4.12 & 0.66 & $.71 * *$ & $.39 * *$ & $(.89)$ & & & \\
\hline 4 & $\begin{array}{l}\text { Information } \\
\text { Exchange } \\
\text { BI - Joint }\end{array}$ & 4.07 & 0.60 & $.58 * *$ & $.49 * *$ & $.78 * *$ & $(.91)$ & & \\
\hline 5 & $\begin{array}{l}\text { Decision } \\
\text { Making }\end{array}$ & 4.02 & 0.65 & $.59 * *$ & $.47 * *$ & $.71 * *$ & $.75 * *$ & (.84) & \\
\hline 6 & $\begin{array}{l}\text { Behavioural } \\
\text { Integration }\end{array}$ & 4.07 & 0.57 & $.69 * *$ & $.49 * *$ & $.91 * *$ & $.92 * *$ & $.89 * *$ & $(.94)$ \\
\hline
\end{tabular}

Note. $* p<.05, * * p<.01 . N=105$. Guest competency $n=105$ 